\title{
Mind the Explanatory Gap:

\author{
Quality from Quantity
}

\author{
Jenny Bunn \\ Department of Information Studies \\ University College London \\ London, UK \\ j.bunn@ucl.ac.uk
}

\begin{abstract}
This paper makes a contribution to the development of computational archival science by thinking about and linking computational and archival thinking. It suggests that archival thinking and the archival problem space encompasses questions about the nature of consciousness, highlighting how these questions seem to be apparent within the fundamental archival principles of respect des fonds, provenance and original order. It seeks to shift attention back to provenance, not just in the sense of where a given object has come from, but also in the sense of the grounds on which it becomes an object and it suggests that the application of computational methods and tools for archival purposes and the integration of computational with archival thinking may offer a way to maintain awareness of this more philosophical dimension in practice.
\end{abstract}

Keywords—consciousness; provenance; ontology

\section{INTRODUCTION}

More than twenty years ago, Terry Cook wrote that 'We [the archives and records management profession] have paper minds trying to cope with electronic realities' [1]. Since then, massive strides have been taken in applying computational methods and tools within the archival problem space. For example, much archival data is encoded and processed in the form of XML, large web archives are automatically harvested, and search is an increasingly sophisticated tool supporting access to collections. Does this mean though that the minds of the archives and records management profession are any less 'paper' than they were in 1994 ?

Also back in 1994, the American Archivist contained an article by Ronald Weissman, who had been asked to predict the technology trends of the next thirty years [2]. He placed particular emphasis on a distinction between information processing and data processing, defined thus; 'Information processing seeks to impute meaning to data, to uncover patterns and to wrestle creatively with ambiguity. By contrast, data processing deals with a few regular types of data and seeks to organize these data in regular and predictable ways via standard report generators' [2].

He went on to point out that; 'Our models of information processing have not changed fundamentally since the mid1970s. [....] the reason so little has changed [...] is that our models of computing have been attuned to the easier problems of data management and our technology has lacked the requisite power to deal with the more difficult and more interesting problems of information processing' [2].

Today our technology most definitely has 'the requisite power to deal with the more difficult and interesting problems of information processing' [2], but the ways in which that information processing is carried out are not necessarily analogous to the information processing, or thinking, that goes on in the human mind, as witnessed by ongoing consideration of the question of artificial intelligence.

For example, a recent big issue raised by the Human Computer Interaction community, concerns the notion of the file [3]. File is a term with which archivists are very familiar and its direct transfer from a paper to a digital environment can perhaps be seen as indicative of 'paper minds trying to cope with electronic realities' [1]. Those raising the issue in 2013 pointed out that they were not the first to do so. As far back as 1981 Frank Halasz and Thomas Moran argued, in a paper entitled 'Analogy Considered Harmful' that, although analogies such as comparing a computer file system to an office filing cabinet might be thought to help individuals 'reason about the workings of the mysterious new computer system', they might rather do more harm than good, preventing these individuals from 'developing an effective understanding of systems' [4]. For, as they went on to point out, 'Computer systems are unique. The tasks they carry out may often be familiar, but their underlying conceptual structures are not' [4].

Whilst this was not exactly the point that Terry Cook sought to highlight with his idea of 'paper minds', it is highlighted here [1]. For, it is suggested that archival thinking and the archival problem space encompasses questions about the nature of consciousness and the workings of the system and that the application of computational methods and tools for archival purposes and the integration of computational with archival thinking may offer a way to maintain awareness of this more philosophical dimension in practice.

\section{PHILOSOPHY ON CONSCIOUSNESS}

Philosophy's investigation of consciousness is of long standing and can be broken down into many different lines of enquiry. One strand within this complex knot circles around the idea of the 'explanatory gap' defined broadly as 'our incomplete understanding of how consciousness might depend upon a nonconscious substrate, especially a physical substrate' 
[5]. There is ongoing disagreement however as to whether it will ever be possible to bridge the gap and what the metaphysical implications of it might or might not be. The explanatory gap therefore feeds into and out of two other philosophical discourses; that around the mind-body problem with the contrary positions of dualism and physicalism, and that of the hard problem of consciousness, of accounting in physical terms for qualia, 'the subjective or qualitative properties of experiences' [6].

On the face of it, the field of archives and records management would appear to have very little to say about the above concerns, but appearances can be deceptive. In the next sections it will be suggested that archival thinking does relate to consciousness in its concern with both the fonds as an organic whole and the record. Also that it maintains its own version of the explanatory gap between the principles of respect des fonds and original order.

\section{ARCHIVES AND RECORDS MANAGEMENT ON CONSCIOUSNESS}

Although the fonds has a long history within archives and records management, it arguably only started to be seen in conceptual terms towards the end of the twentieth century. Shortly after its elevation of status to concept was made official however, particularly by the work of Terry Cook in the early 1990s [7], it started to fall out of fashion; in 2002 Laura Millar announced its 'death' [8] and Peter Horsman spoke of its 'dediscovery' [9]. In both cases the equally old but new usurper of fonds' crown in the conceptual fundament was provenance, of which more later. The preference for provenance could arguably be explained by the fact that it was less tainted by direct association with an imperfect practice. For, the term fonds also equated with the main groups into which archival material was divided to facilitate its management. These groups were supposed to consist of 'the whole of the records, regardless of form or medium, organically created and/or accumulated and used by a particular person, family, or corporate body in the course of that creator's activities and functions' [10], but working out what belonged to one fonds as opposed to another had not always been easy, and it was well recognised that the material of a single creator could be split between many different institutions and hence be in parts not a whole.

More recently though, some archival theorists have started to re-assert and re-examine the fonds in conceptual terms. Geoffrey Yeo, for example, has sought to re-affirm Cook's statement that the fonds should be seen as an intellectual construct and not a physical entity [11]. This he does in the context of problematizing the distinction often suggested between groups of materials labelled fonds and those labelled collections, in terms of fonds being organically accumulated and collections being artificially accumulated aggregations. Although he argues that the 'organic/artificial distinction fails' he does not directly address a seemingly related distinction which surfaces, for example in statements such as the following;

- 'any aggregation that results from conscious human action is an artificial creation'
- 'In this tradition [the archival tradition that sees the fonds as 'an organic growth'], organizations and individuals seem to exercise little or no conscious judgement in assembling a fonds' [11]

In this way there is a subtext around a distinction in levels of consciousness. For Yeo argues that no physical aggregation of records (at least above the level of the item) can be seen to be anything other than 'based on fallible human judgement'; a selective aggregation or collection which has involved conscious decisions [11].

As a concept (and not necessarily a physical aggregation) however, Yeo still seems unwilling to give up the idea of the fonds as archival thinking's 'pre-eminent intellectual construct' [11]. He also links his concept of the fonds, to another important concept within archival thinking, that of the record. Yeo views a record as 'a kind of representation' and sees the fonds as having 'the potential to be just such a record' in the sense that 'it represents the work of an organization or the life of a person or a group of persons' [11]. Distinctions in levels of consciousness are also apparent in Yeo's work on the concept of the record, framed in particular by discussion of 'the intention of the creator' [12]. For example, he points to a divergence of opinion with regards to the 'prevailing mental prototype of a record', one of which places emphasis on 'conscious and procedurally separate construction' and the other on the recordness of records being tied up with a process in which the 'creators have little or no consciousness of recordkeeping purposes' [12].

From these examples, it is suggested that the concept of consciousness is not without some relevance to the archival problem space. Indeed, if we were to take one definition of consciousness as 'a sense of one's personal or collective identity' [13] would it be such a stretch to suggest that the fonds is conceptually such a sense, and that when archivists talk of it representing 'the work of an organization or the life of a person or a group of persons' [11] this might be what they mean? Exploring the implications of equating fonds with consciousness is another project entirely, but for those interested in doing so, it is suggested that the concept might best be approached via the associated concepts of (in philosophical terms) intentionality and transparency, since these also have resonance in archival science.

\section{ARCHIVES AND RECORDS MANAGEMENT ON THE EXPLANATORY GAP}

As has been mentioned above, another archival concept associated with, and sometimes elevated above, that of fonds, is that of provenance. Hence, a relatively common view amongst archival thinkers is to consider that the principle of provenance is; 'the only principle of archival theory. This principle may have an outward application, which is to represent the archival body as it was created by an individual, a group or an organization as a whole. We call this Respect des fonds. The Principle of provenance may also be applied inwardly, respecting the original order given to the documents by the administration which created them. My thesis in this paper is, that both parts of the Principle of provenance form an inseparable whole' [14]. 
Such conceptual unity does not always prove easy to implement however, and arguments, stemming from practice, have often highlighted the conflict that sometimes arises when seeking to follow both the principle of respect des fonds and that of original order. One solution to this problem, implemented in Australia in the 1960s, was to cease to physically implement fonds groups of records [15]. In so doing however, the fonds concept also fell slightly to the wayside, as the emphasis was placed more on provenance, and on a concept with which provenance thereafter became more associated, that of context. The Australian implementation was known as 'the series system' and it made a distinction between record control and context control [15].

To be sure, the series system did resolve the conflict between the two sub-parts of the overarching principle of provenance in practice, but it is less clear that it did so conceptually, since the conflict between inward and outward applications or, as Cook put it, its internal and external dimensions [7], was to some extent by-passed in the shift of focus onto the level above and provenance. One recent attempt to look at the conflict anew has come from Jenny Bunn, who has seen in this tension, a means of accounting for the difficulty, identified by the scholars Maturana and Varela, in understanding 'the regularity of the world we are experiencing at every moment, but without any point of reference independent of ourselves that would give certainty to our descriptions and cognitive assertions' [16], [17]. In this reading therefore, the tension is not resolved in the sense of by-passed, but resolved in the sense of being explained as the maintenance of an awareness of an explanatory gap similar to that highlighted by philosophers in respect of consciousness. How is it that our sense of ourselves and the world around us - our consciousness - is dependent on some physical, external, or 'real' substance or substrate?

\section{SO WHAT?}

In the preceding sections, the author has sought to explain why she thinks that questions about the nature of consciousness are encompassed by archival thinking and the archival problem space. More work will definitely be required to see if engaging with consciousness in philosophical terms will engender any insights that will facilitate archival practice, but such work lies outside the scope of this article. Rather, the next task this article has set itself is to examine the idea that the application of computational methods and tools for archival purposes and the integration of computational with archival thinking may offer a way to maintain awareness of this more philosophical dimension in practice.

\section{THE QUESTION OF PERSPECTIVE}

As stated above, there was a shift in focus when archivists started to implement the series system, emphasizing provenance. This shift meant that the distinction and seeming conflict between provenance's subparts, the internal and external dimensions of respect des fonds and original order, was lost to view to some extent. In many ways this was a useful development. It opened up a field of discourse led by theorists such as Chris Hurley, which started to critically examine provenance in relation to the purpose of archivists' descriptive practices. Such consideration highlighted issues of perspective, of the need for description to be 'grounded in a point of view (an ambience)', but it also led it to a place where provenance was not just multiple, but simultaneously multiple, nay parallel [18]. Losing sight of the explanatory gap (the tension between respect des fonds and original order), failing to mind it in practice, had perhaps removed some of the grounds in which that practice had previously been grounded (albeit imperfectly). Those grounds being an awareness of the fact that archival provenance has meaning, not just in the sense of where a given object has come from, but also in the (more philosophical) sense of the grounds on which it becomes (seen as) an object.

Provenance has recently become of interest within the computer science community as well with the development of the W3C PROV standard [19]. At a recent discussion on the W3C standard by archivists, it was suggested that the standard could 'act as a tool to build common understanding of provenance between the profession and IT professionals' but it was also observed by one individual on reading the standard 'that provenance was not as complex as I thought it was' [20]. Taking these together, another interpretation might be though, that the standard does not demonstrate a 'common understanding of provenance' and that the complexity of what archivists' mean by provenance, its philosophical dimension is not actually fully accounted for by it. The standard states that; 'PROV is a specification to express provenance records, which contain descriptions of the entities and activities involved in producing and delivering or otherwise influencing a given object' [21].

Certainly archivists are interested in such things, particularly with regards to the many physical objects they have been given or loaned or bought, but, as McKemmish points out, they are also interested in objects which are not 'a given', but rather are 'always in a state of becoming' [22].

The suggestion being made here then, is that current specifications of provenance employed/applied within computer science, such as W3C PROV, do not quite capture the complexity of archival provenance, but that perhaps the same is also true of the current specifications of provenance employed/applied within archival science, such as, for example the new conceptual model, Records in Contexts, currently (in late 2016) available in draft form for consultation [23].

\section{INTEGRATING COMPUTATIONAL WITH ARCHIVAL THINKING}

Already in this article, we have discussed much archival thinking, but we have not considered how archivists think. Little research has been done into the cognitive processes of archivists (as a specific subset), but one notable exception to this rule is a study, conducted by Victoria Lemieux which sought to infer a 'model of the archivists' analytic process during arrangement and description', during that is the process in which, in this case, the archivists were seeking to implement the principles and concepts (of fonds, provenance, respect des fonds, original order) discussed above [24].

The study's findings suggested 'a three-stage sense-making model' in which each phase started sequentially, but then 
continued alongside the previous phases until the end of the process. The phases were characterized as:

- Phase 1: From first contact with the records/general overview to the structure of fonds (draft of arrangement decision)

- Phase 2: Confirm/refine structure and physical reordering

- Phase 3: Description and finding aid [24]

There is not as much detail as to the 'thinking' archivists are doing as we would like for the present purpose, but the study does characterize a reliance on abductive reasoning and sees the process in terms of sense making [24].

This characterization would seem to contrast with the following definition of computational thinking, which has been developed by Jeannette Wing and others; 'the thought processes involved in formulating problems and their solutions so that the solutions are represented in a form that can be effectively carried out by an information-processing agent' [25].

Wing has suggested that such thinking should be "part of the skill set of not only other scientists but of everyone else' [26]. Learning such a skill set is now a part of Key Stage 3 Computer Science in the United Kingdom, and a popular revision site describes it as having four cornerstones; decomposition, pattern recognition, abstraction and algorithms [27].

Neither of the above examples give much insight into how thinking happens in a cognitive sense, but they do show how the two communities (archivists and computer scientists) think about their thinking, highlighting differences in what they think they are doing and how they characterize that doing. Further exploration and understanding of these differences would hopefully lead to better communication between the two communities, but for now the task at hand is to demonstrate how the application of computational methods and tools for archival purposes and the integration of computational with archival thinking may offer a way to maintain awareness of the more philosophical dimension of provenance in practice.

\section{ARCHIVAL REPRESENTATION}

With regards to the archival process of arrangement and description, the object of Lemieux's study above, a more common characterization is that of representation. One of the main proponents of this characterization is Elizabeth Yakel, who wrote an article on that subject in 2003 [28]. And more recently, Geoffrey Yeo has also utilised the idea of representation in his conceptualisation of a record as a 'persistent representation of activities, created by participants or observers of those activities or by their authorized proxies' [29]. Above, we have seen how he has also suggested that the fonds might also be seen in a similar way in that 'it represents the work of an organization or the life of a person or a group of persons' [11].

Before using the idea of representation, which he defines in general terms by saying that; 'Representations are "things that stand for something else," and are usually assumed to have some kind of correspondence to the thing they represent' [29], Yeo provides a detailed exploration of the concept, pointing out that it is an issue for many disciplines. For example, he mentions how; 'Psychologists are concerned with mental representations; broadly, systems that are assumed to represent aspects of the external world within the human head' [29].

As we have seen above, there is in fact much to be said about the kind of correspondence there is between aspects of the external world and what goes on within the human head and one issue with representation is the extent to which what is being usually assumed in any seeming representational correspondence is or needs to be made explicit.

Look, for example at the problems that archivists caused themselves by assuming that there was a correspondence between the fonds and a physical grouping of material. That assumption may now have been questioned and discarded, but what other potentially problematic assumptions are there that remain to be seen? In his own undermining of the assumption of the correspondence between fonds and physical aggregations, Yeo does suggest that the fonds might be 'better understood as a conceptual abstraction' but he does not explore the notion of abstraction in detail [11].

As we have seen, abstraction is one of the cornerstones of computational thinking and so perhaps thinking that archival thinking shares this cornerstone might help with any process of putative integration. Abstraction may be a troublesome concept for archivists because it is associated with information hiding and also a lack of attention to detail, neither of which fit terribly well with archivists' view of their mission or their skillset. One computer science textbook writes in these terms; 'Abstraction and information hiding are two sides of the same coin. Information hiding is the practice of hiding details; abstraction is the result with the details hidden' [30].

But it also points out that 'abstraction is the most powerful tool people have for managing complexity' and archivists are increasingly coming to realise, particularly since the development of the continuum model, quite how much complexity they have been trying to manage in their work [30]. Abstraction does allow for filtering out of detail, but that detail is still there in a lower level of abstraction. Then again, abstraction does allow for interoperability and relation between its different layers or levels but it does not assume any kind of correspondence.

One archivist who has explored abstraction in more detail however is Victoria Lemieux who speaks in her 2014 article of the 'abstraction and representation of records and archives' [31]. This article seeks to integrate 'archival theory and practice with information systems theory and practice' [31]. In so doing it characterizes the practice of provenance not in the sense of drawing up 'descriptions of the entities and activities involved in producing and delivering or otherwise influencing a given object', but in the sense of 'building and representing a domain ontology' [21], [31]. Here then the integration of computational with archival thinking, most specifically the consideration of abstraction, reflects back to the archival community that part of what they have always done, albeit perhaps unconsciously, is ontological in nature. Indeed, one of the main points emerging from this work was the development 
of 'an ontological understanding of the record' and the way in which this understanding required the "combined application of Bunge's upper-level "substantive" ontology and Searle's upper-level social ontology' [31]. The message for the archival community is perhaps that the application of computational methods and tools (rather than their own traditional methods and tools) may suit archival purposes better as a way to maintain awareness of the more philosophical aspects of their work in practice.

\section{CONCLUSION}

In this paper, I have sought to make a contribution to the development of computational archival science by thinking about and linking computational and archival thinking. I have suggested that questions about the nature of consciousness are apparent within some archival thinking around fonds, provenance and original order and that thus such questions are encompassed within archival thinking and the archival problem space. I have sought to shift attention back to these questions and to an idea of provenance, not just in the sense of where a given object has come from, but also in the sense of the grounds on which it becomes an object. Moving from an examination of how archivists traditionally characterize their thinking/activity when applying the idea of provenance, I have provided one example in which the integration of computational thinking (in consideration of abstraction) along with archival thinking (in consideration of representation) has shifted attention back to the more philosophical dimension of provenance. It is to be hoped that the narrative thereby constructed will facilitate the acceptance of computational archival science by the archival community and its increased understanding that the application of computational methods may suit their purposes better than traditional ones as a way to maintain awareness of the more philosophical aspects of their work in practice.

\section{REFERENCES}

[1] T. Cook, "Electronic Records, Paper Minds: The Revolution in Information Management and Archives in the Post-Custodial and PostModernist Era," Archives and Manuscripts, vol. 22, no. 2, pp. 300-329, 1994.

[2] R. Weissman, "Archives and the New Information Architecture of the Late 1990s," American Archivist, vol. 57, pp. 20-34, 1994.

[3] R. Harper, S. Lindley, E, Thereska, R. Banks, P. Gosset, G. Smyth, W. Odom and E. Whitworth, "What is a file?," Proc. 2013 Conference on Computer Supported Cooperative Work (CSCW '13), ACM Press, 2013, pp. 1125-1136.

[4] F. Halasz and P. Moran, "Analogy Considered Harmful," Proc. CHI 1981, ACM Press, 1981, pp. 383-386.

[5] R. Van Gulick, "Consciousness," The Stanford Encyclopedia of Philosophy, Spring 2014 Edition, Edward N. Zalta (ed.), http://plato.stanford.edu/archives/spr2014/entries/consciousness/.

[6] A. Kind, "Qualia," The Internet Encyclopedia of Philosophy, ISSN 2161-0002, http://www.iep.utm.edu/.

[7] T. Cook, "The Concept of the Archival Fonds in the Post-Custodial Era: Theory, Problems and Solutions," Archivaria, no. 35, pp. 24-37, 1993.
[8] L. Millar, "The Death of the Fonds and the Resurrection of Provenance: Archival Context in Space and Time," Archivaria, no.53, pp. 1-15, 2002.

[9] P. Horsman, "The Last Dance of the Phoenix, or The De-discovery of the Archival Fonds," Archivaria, no.54, pp. 1-23, 2001.

[10] International Council on Archives, General International Standard Archival Description, Second Edition, Ottawa, 2000.

[11] G. Yeo, "The Conceptual Fonds and the Physical Collection," Archivaria, no. 73, pp. 43-80, 2012.

[12] G. Yeo, "Concepts of Record (2): Prototypes and Boundary Objects," American Archivist, vol. 70, pp. 315-43, 2008.

[13] “Consciousness," http://www.thefreedictionary.com/consciousness

[14] P. Horsman, "Taming the Elephant: An Orthodox Approach to the Principle of Provenance," in The Principle of Provenance: Report from the First Stockholm Conference on Archival Theory and the Principle of Provenance 2-3 September 1993, K. Abukhanfusa and J. Sydbeck, Eds. Sweden, 1994, pp. 51-63.

[15] P. Scott, "The Record Group Concept: A Case for Abandonment," American Archivist, vol. 29 no. 4, pp. 493-504, 1996.

[16] J. Bunn, "Questioning Autonomy: an Alternative Perspective on the Principles which govern Archival Description," Archivaria, vol. 14 no. 1, pp. 3-15, 2014.

[17] H. Maturana and F. Varela, The Tree of Knowledge: the Biological Roots of Human Understanding, Boston and London, Shambhala, 1998.

[18] C. Hurley, "Parallel Provenance," Archives and Manuscripts, vol. 33 no. 1, pp. 110-145 and vol. 33 no. 2, pp. 52-91, 2005.

[19] http://www.w3.org/TR/prov-overview/

[20] Cardigan Continuum, "Pondering Provenance," 2015, https://thecardigancontinuum.wordpress.com/2015/09/22/ponderingprovenance/

[21] W3C Working Group, PROV Model Primer, 2013, http://www.w3.org/TR/2013/NOTE-prov-primer-20130430/

[22] S. McKemmish, "Are Records Ever Actual?" in The Records Continuum: Ian Maclean and Australian Archives First Fifty Years, S. McKemmish and M. Piggott, Eds. Clayton, Ancora Press, 1994, pp. 187203.

[23] International Council on Archives Experts Group on Archival Description, "Records in Contexts A Conceptual Model for Archival Description,” 2016, http://www.ica.org/sites/default/files/RiC-CM0.1.pdf

[24] V. Lemieux, "Visual analytics, cognition and archival arrangement and description: studying archivists' cognitive tasks to leverage visual thinking for a sustainable archival future," Archival Science, vol. 15 no. 1, pp. 25-49, 2013.

[25] J. Wing, "Research Notebook: Computational Thinking - What and Why?" The Link, 2011, http://www.cs.cmu.edu/link/research-notebookcomputational-thinking-what-and-why

[26] J. Wing, "Computational Thinking," Communications of the ACM, vol. 49 no. 3 , pp. $33-35,2006$

[27] "Introduction to computational thinking," BBC Bitesize, http://www.bbc.co.uk/education/guides/zp92mp3/revision

[28] E. Yakel, "Archival representation," Archival Science, vol.3 no. 1, pp. 1$25,2003$.

[29] G. Yeo, "Concepts of Record (1): Evidence, Information and Persistent Representations," American Archivist, vol. 70 no. 2, pp. 315-343, 2007.

[30] N. Dale and J. Lewis, "Computer Science Illuminated," Third Edition, Sudbury, Jones and Bartlett Publishers, 2007.

[31] V. Lemieux, "Toward a "Third Order" Archival Interface: Research Notes on Some Theoretical and Practical Implications of Visual Explorations in the Canadian Context of Financial Electronic Records," Archivaria, vol. 78, pp. 53-93, 2014. 